TURIZAM

Volume 19, Issue 2

$71-83$ (2015)

\title{
Assessment of Sustainability of Sports Events (Slovenia)
}

\author{
Aleksandra Golob, Miha Lesjak, Daša Fabjan, Tadeja Jere Jakulin*, Igor Stamenković** \\ Received: February 2015 | Accepted: May 2015
}

\section{Abstract}

Events industry plays an important role in nowadays economy and can have a substantial impact for a successful business; in addition, sustainability-oriented tourism is becoming an important component of development and planning of a tourist destination. Thus, organizing sustainability-oriented events is crucial and should focus on the zero waste event management and consider as many elements of sustainable development as possible. The same stands for organizing sports events.

The aim of this paper was to find out to which level the organizers of existing sports events in Slovenia are taking into account different domains of sustainable development. Answering to a common questionnaire the organizers gave us a feedback considering four main areas: environmental, social, cultural, and economic criteria. The plan was to determine the level of sustainability of three sports events and compare them to each other according to the outstanding areas as well as to draw the attention to the importance of organizing sustainability-oriented sports events and minimizing negative effects of those.

Since the field of research is complex, dynamic, and has an interdisciplinary character the results were attained using the DEX software which supports a qualitative approach and allows the modelling of complex decision-making processes with a large number of parameters and alternatives. Such methodology enables the input of a preliminary set of sustainability criteria and can be used as a support when deciding on the evaluation of sustainability of events in general.

Key words: sustainable tourism, sustainable events, sports events, DEXi program, Triple Bottom Line method

* UP FTŠ Turistica, Obala 11a, 6320 Portorož, Slovenia, Corresponding author:aleksandra.golob@gmail.com

** Faculty of Sciences, Department of Geography, Tourism and Hotel Management, Trg Dositeja Obradovića 3, 21000 Novi Sad, Serbia 


\section{Introduction}

Many events are organized every day, either during the high tourist season or beyond. As Dickson and Arcodia (2010) state "it is clear that the event industry has experienced phenomenal growth over the past decade in terms of number, diversity and popularity of events on offer." (Dickson, Arcodia, 2010, 237) The same confirms also Getz (1997) by saying that with the increased number of events the competitive advantage and added value are keys to differentiation from the competition. Both value added and competitive edge of events can be achieved by implementing one or more elements of sustainable development, which will distinguish one event from the others (Blešić et al., 2014).

When finding out to which level the organizers of sports events are taking into account different domains of sustainable development, the attention should also be drawn to the need for comprehensive evaluation of the impacts of sustainability-oriented events (Stamenković, 2014). Thus our attention was paid to three pillars of sustainable development (economic, socio-cultural and environmental) or what is known as Triple Bottom Line (TBL) method.

The objective of the research was to graphically present the areas in which the sustainable events in question stand out, and to define a basis on which the event organizers can improve the implementation of sustainable solutions in the pre-event organizing phase.

Through this paper we tried to get as many information as possible on the sustainable development in sports events. In this context we expected significant progress in the quality of sustainability-oriented sports events and wanted to objectively measure the impacts. Three sports events were included in our survey; all of these are organized in Slovenia (the Ljubljana marathon, European handball festival Eurofest Izola, and a running event Povežimo soline in Piran). Ljubljana Marathon is the largest Slovenian running event which takes place at the end of October in the capital city of Slovenia. Every year the event attracts more than 20,000 runners. For the last 10 years the recreational running and hiking event Povežimo soline has been connecting the Sečovlje salt-pans and the Strunjan salt-pans, both in the Municipality of Piran. The trail with a distance of $10 \mathrm{~km}$ attracts about 1,500 runners every year. Eurofest (the European handball festival) is a traditional sports event, which is held in the first week of July in two towns of the Slovenian coast (Izola and Koper). For over twenty years the handball festival has been organized for young athletes, and has been attracting more than 3,0oo participants from all around the world.

The so called zero waste level of these events was analyzed using the DEXi computer programme which enables the analysis of qualitative data based on multi-attribute decision models (Bohanec, 2012). This program was used for decision support on choosing the most sustainable event. Our analysis was based on a preliminary set of sustainability criteria on which the level of sustainability-orientation was determined.

\section{Sustainable development of tourism}

Sustainable tourism is gaining importance rapidly all around the world, even more the sustainability approach is one of the priority areas in tourism development.

Many authors (Hede, 2007; Sherwood, 2007; Raj, Musgrave, 2009; Bailey, Richardson, 2010; Musgrave, 2011; Gibson et al., 2012; Menna et al., 2012; Garcia de Leaniz et al., 2012; Pernecky, Lück, 2013; Andersson, Lundberg, 2013) as well as different documents for organizing sustainable events (BS ISO 20121 Event Sustainability Management System - Requirements with guid- 
ance for use, or CSA Z2010 Requirements and Guidance for Organizers of Sustainable Events) are highlighting the three pillars of sustainable development: economic, socio-cultural and environmental aspects in connection with TBL.

One of the first and most cited definition of sustainability was created in 1987 by the Brundtland Commission or World Commission on Environmental and Development founded by the UN. This commission defined sustainable development as development that "meets the needs of the present without compromising the ability of future generations to meet their own needs." (WCED, 1987, 27) A very similar definition was given by Getz $(1997,70)$, a guru in the field of event management, who defines sustainable development as "changes (e.g. physical or economic development - not necessarily growth) that will generate benefits but not impede the ability of future generations to meet their needs and enjoy a comparable or better quality of life and environment." According to the concept of sustainable development Stubelj Ars and Bohanec (2010) agree that tourism is sustainable when development meets the needs of local residents and present tourists while protecting future opportunities.

Buckley (2012) draws attention to forecasting the future of sustainable tourism. He stresses out that the key consideration is that both tourism and sustainability are changing more rapidly than the tourism industry adopts sustainability improvements. Buckley's research relates to the findings of Sharpley $(2009,220)$, who noted that there is "limited evidence of its implementation in practice."

Similar can be said for the events industry, mainly due to the lack of sharing of good practices of sustainability-oriented events (Musgrave, 2011; Getz, 2012; Mair, Laing, 2012) or in other words, "the event industry needs to focus further at achieving more sustainable practice" (Dickson, Arcodia, 2010, 243).

\section{Sustainability-oriented events}

The developmental role of sustainability has become very important to tourism economies in recent years, and presents the event industry with many opportunities and challenges (Pernecky, Lück, 2013).

Further review of the published references on events did not give many definitions of sustainability-oriented events. Raj and Musgrave $(2009,25)$ propose the following definition for responsible events: "events sensitive to the economic, sociocultural and environmental needs within the local host community, and organized in such a way as to optimize the net holistic (positive) output." Golob and Ivankovič (2013) define sustainable events as a whole sum of units of all three pillars of sustainable development (environmental, economic and socio-cultural) that are logically integrated in planning as well as in organizing and realization of events.

Triple Bottom Line (TBL) method is used to identify the impacts of sustainable development and to measure its efficiency. A Triple Bottom Line term was coined by Elkington (1997) in his book Cannibals with Forks: the Triple Bottom Line of 21st Century Business. He points out that the TBL method can be used for measuring and reporting the performance of company in relation to economic, social and environmental parameters. Similarly consider also Menna et al. (2012), who claims that the key objectives of sustainable development are usually represented in terms of TBL strategy.

In their work Raj and Musgrave (2009) introduced the concept of responsible (sustainable) event, which contributes to the local sustainable development through TBL. This is shown in Figure 1. The concept illustrates sustainable events in the intersection of all three circles. 


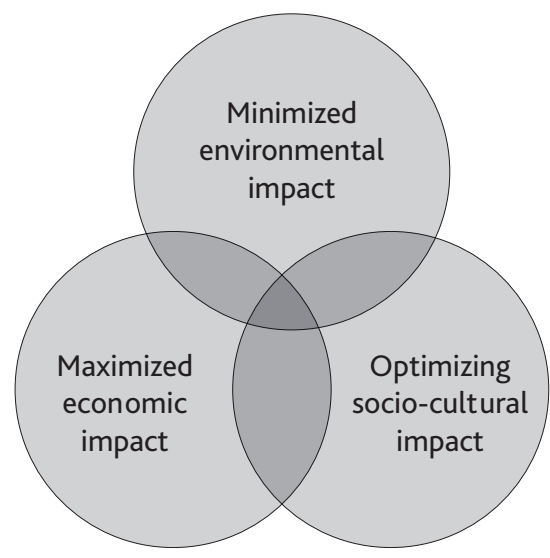

Figure 1. Responsible (sustainable) events Source: Raj, Musgrave $(2009,25)$

According to the proportionality of circles, it can be assumed that each element is equal and should be treated in the same proportion also in practice.

Fyall and Jago (in Gibson et al., 2012) suggested that to understand sustainability in relation to sports tourism, we need to understand the impacts of sports and tourism in terms of the triple bottom line, and to pay attention to the influence of the external environment on sports and tourism.

Following the above said there are different structures to the objectives, thus it is important to monitor the performance of sustainability-oriented sports events, and later to comprehensively manage the impacts of such events.

\section{Managing the impacts of sustainable events}

When talking about managing the impacts of events one comes across the term zero waste event management, which is a very complex and dynamic process. According to Musgrave (2011, 269) the implementation of sustainable principles within events "must be integrated and planned, and should mirror the elements of quality management frameworks." Organizers of the sustainability-oriented events have many possibilities for using sustainable measures and solutions, and documenting the environmental impact assessment; such as for example: separate waste collection, use of energy-saving technologies, taking care of water consumption, carbon footprint calculation, the inclusion of local providers, analysing venues capacity, and so on.

The field of sustainable environmental management of events was investigated by several authors (Hede, 2007; Laing, Frost, 2010; Mair, Jago, 2010; Park, Boo, 2010; Sherwood, 2007, Gibson et al., 2012). Getz (2012) states that the most recently developed environmental dimension of event impact leads directly to the implementation of sustainability criteria (encompassing TBL, corporate social responsibility, and green criteria) as already researched in books by Jones (2010), Raj, Musgrave (2009), and Goldblatt, Goldblatt (2011).

As one can read in Della Lucia (2013) the international literature has been dealing with the economic impacts of events for almost fourty years. While according to Gibson et al. (2012) tourists' perception, motivation and satisfaction should be considered as part of the social pillar of sustainable development. More specifically, tourism demand and social sustainability 
play a role in "understanding the relationship between tourists' motives and the destination's ability to address those motives and consequently the tourists' satisfaction with their visit. However in general, the social field often focuses on the positive and negative effects perceived by the local population" (Gibson et al., 2012, 162, 168).

Hermann et al. (2011) investigated responsible tourism indicators in the event sector. They identified 15 responsible tourism indicators. If we mention just a few best rated: the creation of local employment, host community engagement, management of noise, landscape management and the use of indigenous fauna and flora, recycling, using local products and services, energy-saving initiatives, etc., it is obvious that respondents devoted attention to all three pillars (economic, socio-cultural and environmental).

Similarly, Hall (2011) reminds us about the development of tourism as an integral part of economic, social and environmental development strategy.

Considering all the above said it is clear and logical that also the level of sustainability of sports events should be treated from all three aspects of sustainable development. In our research three sports events were analyzed by three attributes: economic, socio-cultural and environmental. Based on these a level of sustainability orientation was assessed for all three events.

\section{Methodology}

To analyze the individual aspects of sustainability criteria we followed the approach of modelbased decision support: we developed a model for the analysis and evaluation of the sustainability of sports events. The attributes and subattributes for each aspect had to be defined. These were given in a form of questions to the organizers of the three chosen sports events in Slovenia (The Ljubljana marathon, the European handball festival Eurofest, and the running event Povežimo soline in Piran).

The data to analyse these events were obtained from members of organizing committees of sports events in Slovenia in 2014. All organizers were responsible for the planning, organization, management, and control of the studied events. They were sent structured questionnaires, and all of these were returned. The questionnaire was divided into six subsets of attributes that covered the three sustainability pillars. The subsets consisted of sub-attributes in the form of questions. The respondents had to rank these sub-attributes to point out the most important element of one criteria/attribute, and then assess the level of their effort in implementing the solutions suggested by each question for their event.

The criteria and consequently the attributes for multi-criteria modelling were defined after a study of literature (Raj, Musgrave, 2009; Dickson, Arcodia, 2010; Laing, Frost, 2010; Mair, Jago, 2010; Hermann et al., 2011; Musgrave, 2011; Gibson et al., 2012; Mair, Laing, 2012; Andersson, Lundberg, 2013; Pernecky, Lück, 2013).

When planning the model of attributes we followed the four steps of building a DEXi model as explained by Bohanec (2003): 1) identifying the attributes, 2) structuring the attributes, 3) defining attribute scales, and 4) defining the decision rules. The qualitative attributes which are structured hierarchically can take also discrete symbolic or descriptive value. However, for defining attribute scales we used words. Bohanec (2012) further explains that the aggregation of attributes up the tree is defined by decision rules.

In our model, we used a maximum four-grade value scale for modelling the tree of criteria which in the end represented the main evaluation elements. The value scales are shown in Table 1. 
Table 1. Value scales used in the attribute model

\begin{tabular}{|l|l|}
\hline Attributes & Value scale \\
\hline $\begin{array}{l}\text { Environmental } \\
\text { Sustainability }\end{array}$ & $\begin{array}{l}\text { unacceptable, acceptable, } \\
\text { good, excellent }\end{array}$ \\
\hline $\begin{array}{l}\text { Transport } \\
\text { Cultural }\end{array}$ & low, medium, high, highest \\
\hline $\begin{array}{l}\text { Social } \\
\text { Economical }\end{array}$ & $\begin{array}{l}\text { worse, medium, } \\
\text { better, excellent }\end{array}$ \\
\hline
\end{tabular}

After obtaining the answers from respondents these were analyzed using DEXi ${ }^{1}$ software. The level of importance of each attribute was then determined using MS Excel.

The program DEXi evaluates variants. As said in our case these were three sports events in Slovenia. The organizers were asked to fill in the questionnaires, formulated according to the recommendations of "Zero Waste Guidelines for Events and Festivals", which were a result of the EU cross border project „Zero Waste - Adriatic net for events and festivals“. The questionnaire was adapted to the requirements of the computer program DEXi. Thus a smaller number of attributes was used. Attributes with less significance were excluded from the list following selective considerations.

\section{Results}

The assessment of the events' sustainability level was analysed on three sports events using the developed attribute model. The answers and criteria tree are presented in Table 2.

After running the analysis in the program DEXi some interesting findings were obtained. The characteristics of the three sports events in Slovenia and the results of their assessment are presented below.

As can be seen only one event was rated as good, while the other two were rated as acceptable. There is no excellent event among the three variants, which leaves space to future improvements in sustainability for all three events.

Tables 3 to 5 show the weaknesses and strengths of each event. The later is crucial to describe to which level the organizers of existing sports events are taking into account different elements of sustainable development. From Table 3 one can see that Ljubljana marathon event does not have any weak points. For this reason this event obtained the highest assessment among all three. Strong points were found in all sustainability criteria (environmental, social, economical), excluded was only cultural attribute. If the organizer paid more attention to the cultural criteria, the event would obtain the rate excellent. This shows that for the sustainable approach it is very important to reach balance between all sustainability criteria. This also confirms what Stubelj Ars and Bohanec (2010) defend that all three dimensions (economic, social and environmental) should be balanced in order to achieve sustainable development.

1 DEXi is an interactive computer program using qualitative (symbolic) attributes instead of quantitative ones (Bohanec, Rajkovič, 1995); in our case only descriptive variables were used. 
Table 2. Assessment of the sustainability of three sports events

\begin{tabular}{|c|c|c|c|c|c|}
\hline DEXI & \multicolumn{5}{|c|}{ zero waste for events } \\
\hline \multicolumn{6}{|c|}{ Evaluation results } \\
\hline \multicolumn{3}{|c|}{ Attribute } & Ljubljana marathon & Povežimo soline & Eurofest \\
\hline \multicolumn{3}{|c|}{ Zero waste for events } & good & acc & acc \\
\hline & \multicolumn{2}{|c|}{ Environmental attributes } & high & high & low \\
\hline & & Minimization of water consumption & high & medium & low \\
\hline & & Minimization of waste quantity & high & high & medium \\
\hline & & Separate collection of waste & high & high & low \\
\hline & & Biodiversity preservation & highest & highest & medium \\
\hline & \multicolumn{2}{|l|}{ Social } & better & medium & better \\
\hline & & $\begin{array}{l}\text { Safety and security } \\
\text { (visitors and staff health and safety) }\end{array}$ & excellent & excellent & excellent \\
\hline & & Educational content & excellent & worse & better \\
\hline & & Participation of local community & better & excellent & excellent \\
\hline & & "Waste" donations & better & worse & worse \\
\hline & \multicolumn{2}{|l|}{ Cultural } & high & high & high \\
\hline & & Heritage preservation and inclusion & high & highest & high \\
\hline & & Local tradition preservation & medium & high & medium \\
\hline & & Traditional events & high & low & medium \\
\hline & & Multicultural character & high & high & highest \\
\hline & \multicolumn{2}{|c|}{ Economical } & high & high & highest \\
\hline & & Strenghten the local economy & excellent & excellent & excellent \\
\hline & & Local decision-makers & better & worse & worse \\
\hline & & Possibility to create new "green jobs" & medium & worse & medium \\
\hline & & Event attractiveness (evaluation of event) & excellent & worse & better \\
\hline
\end{tabular}

Table 3. Selective explanation: weak and strong points for the Ljubljana marathon

\begin{tabular}{|c|c|c|}
\hline DEXI & \multicolumn{2}{|l|}{ zero waste for events } \\
\hline \multicolumn{3}{|c|}{ Weak points } \\
\hline \multicolumn{3}{|l|}{ none } \\
\hline \multicolumn{3}{|c|}{ Strong points } \\
\hline \multicolumn{2}{|l|}{ Attribute } & Ljubljana marathon \\
\hline & Biodiversity preservation & highest \\
\hline & $\begin{array}{l}\text { Safety and security } \\
\text { (visitors and staff health and safety) }\end{array}$ & excellent \\
\hline & Educational content & excellent \\
\hline & Strenghten the local economy & excellent \\
\hline & Event attractiveness (evaluation of event) & excellent \\
\hline
\end{tabular}

Most weak points of the running event called Povežimo soline represent economical attributes (local decision-makers, possibility to create new "green jobs", and event attractiveness), while other attributes (social, cultural and environmental) have only one weak point each (Table 4). The strong points are equally spread among all criteria. 
Table 4. Selective explanation: weak and strong point for the event Povežimo soline

\begin{tabular}{|l|l|l|}
\hline \multicolumn{2}{|l|}{ DEXI } & \multicolumn{2}{|l|}{ zero waste for events } & Povežimo soline \\
\hline \multirow{4}{*}{ Attribute } & Educational content & worse \\
\hline \multirow{4}{*}{} & "Waste" donations & worse \\
\cline { 2 - 3 } & Traditional events & low \\
\cline { 2 - 3 } & Local decision-makers & worse \\
\cline { 2 - 3 } & Possibility to create new "green jobs" & worse \\
\cline { 2 - 3 } & Event attractiveness (evaluation of event) & worse \\
\hline Strong points & & \\
\hline \multirow{4}{*}{ Attribute } & Biodiversity preservation & Povežimo soline \\
\hline \multirow{5}{*}{} & $\begin{array}{l}\text { Safety and security } \\
\text { (visitors and staff health and safety) }\end{array}$ & highest \\
\cline { 2 - 3 } & Participation of local community & excellent \\
\cline { 2 - 3 } & Heritage preservation and inclusion & excellent \\
\cline { 2 - 3 } & Strenghten the local economy & highest \\
\hline
\end{tabular}

The weak points of the event Eurofest are mostly environmental attributes, while social and economic attributes only have one weak point. The cultural attributes are excluded. It is very interesting that among strong points there is no environmental attribute. Later means that the organizer does not pay enough attention to environmental attributes (Table 5).

Table 5. Selective explanation: weak and strong point for the event Eurofest

\begin{tabular}{|c|c|c|}
\hline DEXI & \multicolumn{2}{|l|}{ zero waste for events } \\
\hline \multicolumn{3}{|c|}{ Weak points } \\
\hline \multirow[t]{6}{*}{ Attribute } & & Eurofest \\
\hline & Environmental attributes & low \\
\hline & Minimization of water consumption & low \\
\hline & Separate collection of waste & low \\
\hline & "Waste" donations & worse \\
\hline & Local decision-makers & worse \\
\hline \multicolumn{3}{|c|}{ Strong points } \\
\hline \multicolumn{2}{|l|}{ Attribute } & Eurofest \\
\hline & $\begin{array}{l}\text { Safety and security } \\
\text { (visitors and staff health and safety) }\end{array}$ & excellent \\
\hline & Participation of local community & excellent \\
\hline & Multicultural character & highest \\
\hline & Strenghten the local economy & excellent \\
\hline
\end{tabular}

The DEXi decision modelling program also produces radar charts so that the results can be graphically presented (Stubelj Ars and Bohanec, 2010). Charts enable a graphic comparison of the combination of three to six selected attributes. 
LJUBLJANA MARATHON

Environmental attributes

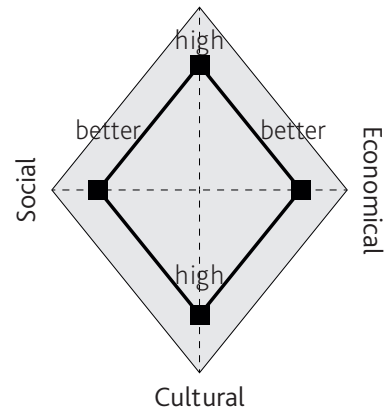

POVEŽIMO SOLINE

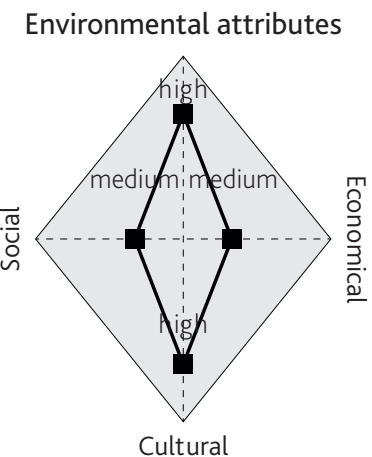

EUROFEST

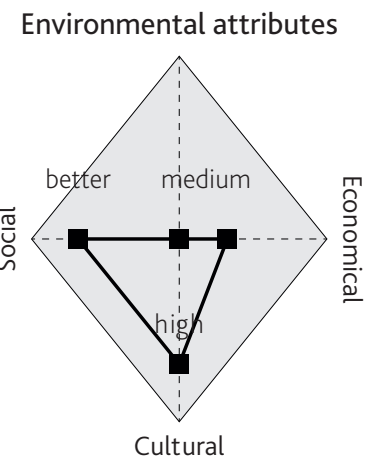

Graph 1. Assessment of events with respect to environmental, social, cultural and economical attributes.

In Graph 1 there are three charts which present the four main attributes: environmental, social, cultural and economic, for each event. It can be seen that the Ljubljana marathon has the best overall assessment compared to other two events. So it is possible to deduce that the Ljubljana marathon is more successful in implementing sustainability solutions compared to the event Povežimo soline and the event Eurofest.

Graph 2 presents how much attention organizers pay to environmental criterion. The Ljubljana marathon stands out in a positive way, while the event Eurofest does not seem to pay enough attention to environmental attributes. This indicates the need to improve zero waste management and introduce measures and solutions to improve the quality of environmental orientation.

LJUBLJANA MARATHON

Environmental attributes

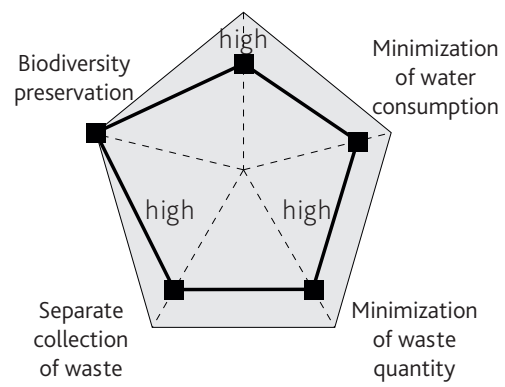

POVEŽIMO SOLINE

Environmental attributes

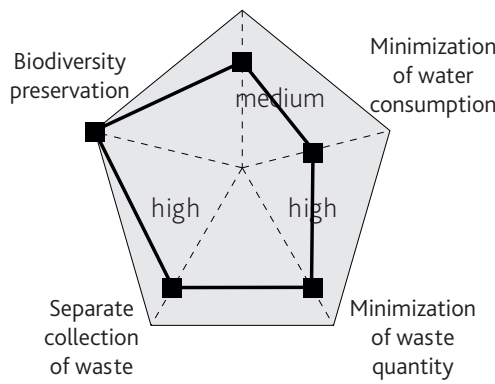

EUROFEST

Environmental attributes

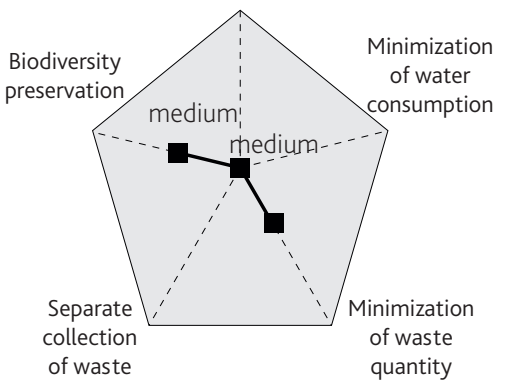

Graph 2. Evaluation of events with respect to environmental attributes (biodiversity preservation, separate collection of waste, minimization of waste quantity, and minimization of water consumption).

Graph 3 consists of three charts to compare the social attributes of each event. These are waste donations, participation of local community, educational content, and safety and security. The Ljubljana marathon is estimated as the best event concerning social criterion, however the event Povežimo soline is estimated as the worst. Even so, this criterion was the best estimated compared to other three. Even more, it is very interesting that social attributes are rated as the best and most represented in all analyzed events, which can also be noticed in Table 6 . 
LJUBLJANA MARATHON

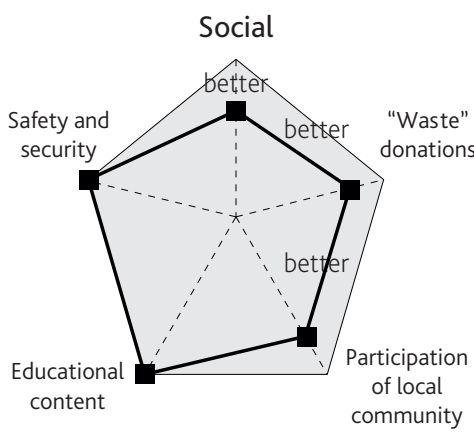

POVEŽIMO SOLINE

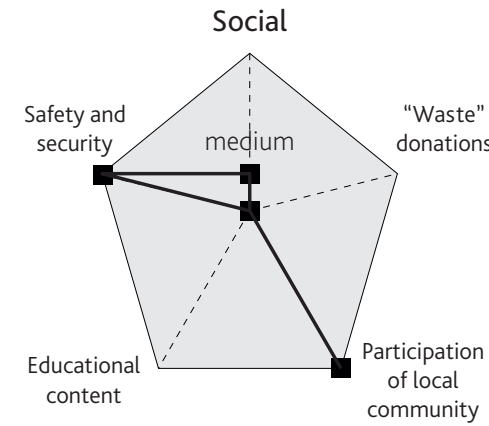

EUROFEST

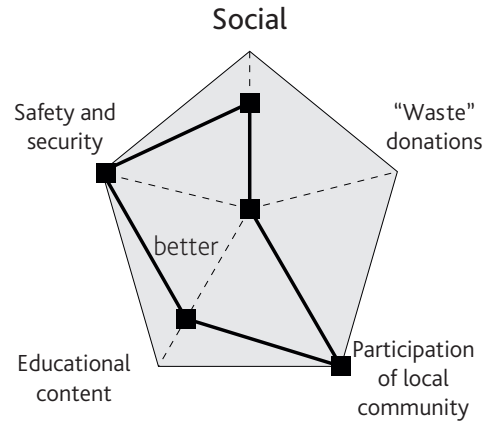

Graph 3. Evaluation of events with respect to social attributes (waste donations, participation of local community, educational content, and safety and security).

LJUBLJANA MARATHON

Cultural

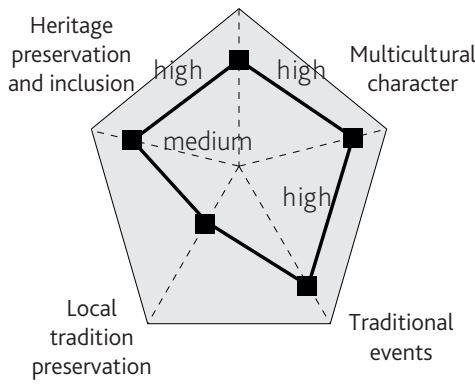

POVEŽIMO SOLINE

Cultural

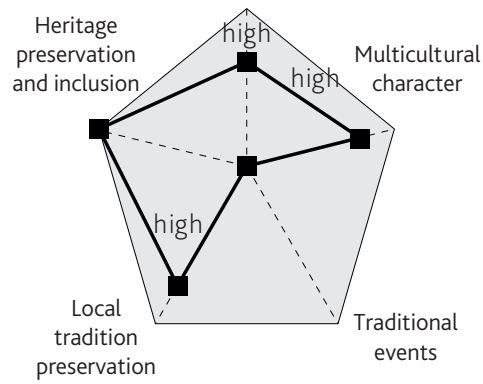

EUROFEST

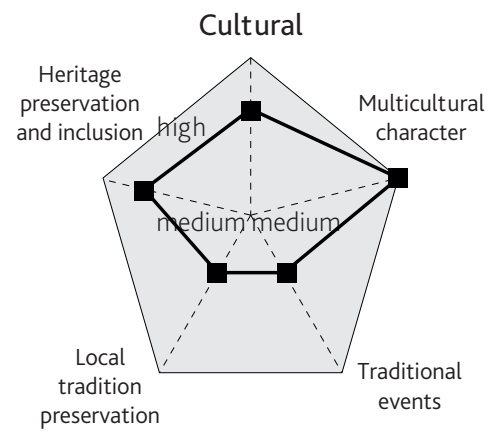

Graph 4. Evaluation of events with respect to cultural attributes (multicultural character, traditional events, local tradition preservation, and heritage preservation and inclusion).

Graph 4 refers to the cultural criteria and compares the multicultural character, traditional events, local tradition preservation, and heritage preservation and inclusion of chosen events. All three events were rated high, but we can see again that the Ljubljana marathon has a slightly better rating than other two. All organizers pay attention to cultural attributes.

Finally, Graph 5 shows the ratings of the economical attributes. The Ljubljana marathon and the event Eurofest have a better economic management system than the event Povežimo soline. The Povežimo soline chart area covered by the polygon line is rather small which indicates the need to improve its economical attributes (event attractiveness, local decision-makers, and possibility to create new "green jobs"). The Ljubljana marathon again stands out in a positive way, while the event Povežimo soline remains with rather poor ratings. The same could be noticed also in Graph 1.

Based on the analysis of the strengths and weaknesses as well as graphic comparison, we managed to identify the most and the least represented sustainability criteria. We found out that the organizers devoted more attention to social criterion, while it is quite impossible to summarize a common estimaton for criterion representing weakness as no one stands out. 
LJUBLJANA MARATHON

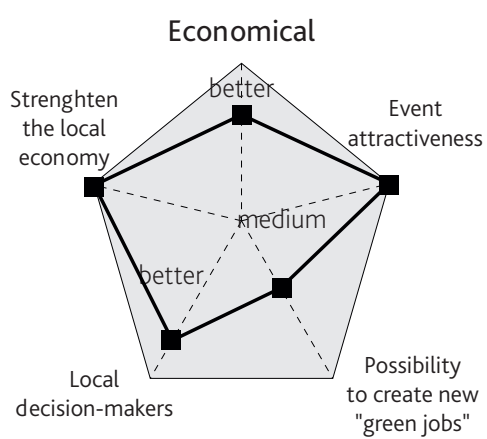

POVEŽIMO SOLINE

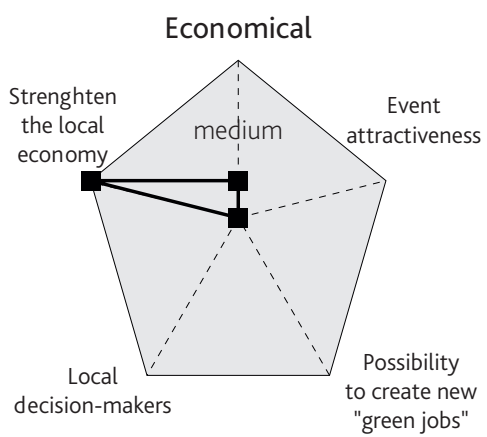

EUROFEST

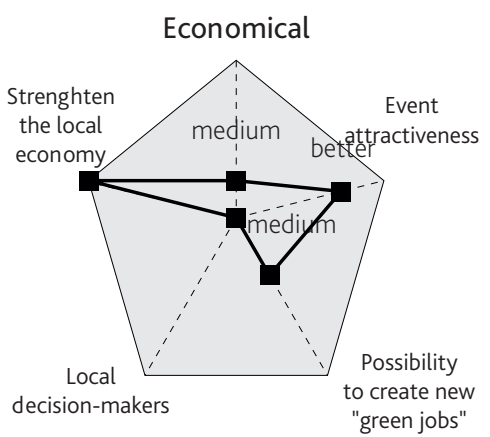

Graph 5. Evaluation of events with respect to economical attributes (event attractiveness - evaluation of events, possibility to create new "green jobs", local decision-makers, and strengthen the local economy).

Table 6. The worst and the best criteria of sustainable events

\begin{tabular}{|l|l|l|}
\hline Events & The best criterion & The worst criterion \\
\hline Ljubljana marathon & Social / Economic & $/$ \\
\hline Povežimo soline & Social & Economic \\
\hline Eurofest & Social & Environmental \\
\hline
\end{tabular}

\section{Conclusions and implications for research}

Our research focused on assessment of the sustainability-orientation of sports events in Slovenia. We used a multi-attribute qualitative model to estimate the level of sustainability of three sports events. This model is flexible in the sense that its hierarchical structure and decision rules enable its application to other potential case studies for all types of events, e.g. political, sports, recreational, educational, cultural, entertainment, business (adopted from Getz, 1997) with just small adjustments.

Research has shown that the organizers focus most of their attention to social criteria as it turned out to have the most positive ratings (strong points), while other criteria were represented in relatively equivalent percentages. With the analysis of the data using DEXi program we demonstrated that an equivalent or balanced treatment of the sustainability criteria is necessary in order to obtain the best estimate of event's sustainability orientation.

As well it is important that the organizers include the sustainable elements already in the development phase of the event. Based on this assumption the process of assessing the sustainability of events is very important. The strengths and weaknesses of individual sustainability criterion should be determined, and weaknesses improved in the planning stage of the next event.

We have proven that the monitoring of the impacts of sustainable events can be run effectively using DEXi program where criteria with subattributes were set as descriptive variables.

This methodology can and should be used among the organizers of events who can arbitrarily change the attributes, add or omit them, which is logical due to the variety of events and their diversity and ability to monitor sustainability criteria. 
Golob and Jere Jakulin (2014) studied the legislation of events and came to the conclusion that the future development and regulation of the legislative system of sustainability-oriented events should not be suppressed. This goes along with Hermann et al. (2011), who stated that if responsible tourism guidelines have proven effective in other sectors of the tourism industry, their effective implementation in the event sector will be also useful.

Many studies highlight the lack of academic research and sharing of good practices of sustainability-oriented events in the literature, e.g. Musgrave (2011), Getz (2012), and Mair, Laing (2012). Gibson et al. (2012) note that the environmental impacts associated with sports events is the most underdeveloped aspect in the existing literature. Thus, the future research should continue with trying to find an answer to what criteria must be met for an event to be sustainability-oriented, in order to present good practices in the field of event management from the perspective of sustainable development. By setting the minimum standards for sustainability-oriented events, comparability of events on a larger scale would be possible, and thus the event's competitive advantage could be achieved much easily.

\section{References}

Andersson, T. D., Lundberg, E., 2013. Commensurability and sustainability: Triple impact assessments of a tourism event. Tourism management 37, 99-109.

Bailey, E., Richardson, R. 2010. A new economic framework for tourism decision making. Tourism and Hospitality Research 10(4), 367-376.

Blešić, I., Pivac, T., Đorđević, Stamenković, I., Janićević, S. 2014. Cultural events as part of cultural tourism development. Case study: Sombor and Apatin (Serbia). Acta geographica Slovenica Special issue - SyCULTour 2014, 54-2.

Bohanec, M., Rajkovič, V. 1995. Večparameterski odločitveni modeli. Organizacija in kadri 28(7), 427-438.

Bohanec, M. 2003. A function-decomposition method for development of hierarchical multi-attribute decision models. Decision Support Systems 36, 215-223.

Bohanec, M. 2012. Odločanje in modeli. Ljubljana: DMFA.

BS ISO 20121: 2012 2012. Event sustainability management systems - Requirements with guidance for use. British standard: International Organization for Standardization.

Buckley, R. 2012. Sustainable tourism: Research and reality. Annals of Tourism Research 39(2), $528-546$.

CSA Standards Z2O10 - 10 2010. Requirements and guidance for organizers of sustainable events. Canada: Canadian Standards Association.

Dickson, C., Arcodia, C. 2010. Promoting sustainable event practice: The role of professional associations. International Journal of Hospitality Management 29, 236-244.

Della Lucia, M. 2013. Economic performance measurement system for event planning and investment decision making. Tourism Management 34, 91-100.

Elkington, J. 1999. Cannibals with forks: the triple bottom line 21st century business. Oxford: Capstone.

Garcia de Leaniz, P. M., Perez Lusi, A., Rodriguez del Bosque, I. 2012. Analysis of the corporate social responsibility practice in the tourism sector: case study. Cuadernos de Turismo 30, 309-312.

Getz, D. 1997. Event Management and Event Tourism. New York: Cognizant Communication Corporation. 
Getz, D. 2012. Event Studies: discourses and future directions. Event Management 16, 171-197.

Gibson, H. J., Kaplanidou, K., Jin Kang, S. 2012. Small - scale event sport tourism: A case study in sustainable tourism. Sport Management Review 15, 160-170.

Golob, A., Ivankovič, G. 2013. Družbena odgovornost kot konkurenčna prednost trajnostne prireditve - študija primera podjetja Vivo catering. Turizem, izobraževanje in management (elektronski vir): soustvarjanje uspešne poslovne prihodnosti: 4. Znanstvena konkurenca z mednarodno udeležbo, 24.-25. oktober 2013, Portorož. Univerza na Primorskem: Koper.

Golob, A., Jere Jakulin, T. 2014. Standardization and classification of events in tourism based on a systems approach. Journal of Applied sciences Singidunum 11(1), 67-73.

Hall, R. D. 2011. Tourism development in contemporary Central and Eastern Europe: challenges for the industry and key issues for researchers. Human geographies - Journal of Studies and Research in Human Geography 5.2, 5-12.

Hede, A. M. 2007. Managing special events in the new era of the triple bottom line. Event Management 11(1/2), 13-22.

Hermann, U. P., Geldenhuys, S., Coetze, W. J. L. 2011. Are responsible tourism indicators in the event sectors applicable? The case study of Gauteng Province, South Africa. African Journal of Business Management 5(22), 9616-9622.

Jones, M. L. 2010. Sustainable event management: A practical guide. New York: Earthscan.

Laing, J., Frost, W. 2010. How green was my festival? Exploring challenges and opportunities associated with staging green events. International Journal of Hospitality Management 29(2), 261-267.

Mair, J., Jago, L. 2010. The development of a conceptual model of greening in the business events tourism sectors. Journal of Sustainable tourism 18(1), 77-94.

Mair, J., Laing, J. 2012. The greening of music festivals: motivations, barriers and outcomes. Applying the Mair and Jago model. Journal of Sustainable Tourism 2o(5), 683-70o.

Menna, C., Asprone, D., Jalayer, F., Prota, A., Manfredi, G. 2012. Assessment of ecological sustainability of a building subjected to potential seismic events druring its lifetime. Int. J Life Cycle Assess. http://wpage.unina.it/fatemeh.jalayer/Publicationsfile/ecological\%2osusrainability.pdf (10. 4. 2013.).

Musgrave, J. 2011. Mowing Towards responsible events management. Worldwide Hospitality and Tourism Themes 3(3), 258-274.

Park, E., Boo, S. 2010. An assessment of convention tourism's potential contribution to environmentally sustainable growth. Journal of Sustainable Tourism 18(1), 95-114.

Pernecky, T., Lück, M. 2013. Events, society and sustainability: critical and contemporary approaches. New York: Routledge.

Raj, R., Musgrave, J. 2009. Event management and sustainability. CAB International. London, UK.

Sharpley 2009. Tourism development and the environment: beyond sustainability? London: Earthscan.

Sherwood, P. 2007. A Triple Bottom Line Evaluation of the Impact of Special Events: The development of Indicators, PhD Thesis. Victoria University: Center for Hospitality and Tourism Research. http://vuir.vu.edu.au/1440/1/Sherwood.pdf (15. 7. 2013.).

Stamenković, I. 2014. Multi-stejkholderski pristup efektivnosti organizacije događaja kao faktor uspešnosti destinacijskog turističkog proizvoda, Doktorska disertacija, Departman za geografiju, turizam i hotelijerstvo, PMF, Novi Sad.

Stubelj Ars, M., Bohanec, M. 2010. Towards the ecotourism: A decision support model for the assessment of sustainability of mountain huts in the Alps. Journal of Environmental Management 91(12), 2554-2564.

WCED 1987. Our common future. Oxford: Oxford University Press. 